days than they have ever been and it is our task to help to keep them fit through adolescence to adulthood, by example, teaching, and setting standards of meal content, cleanliness and good handling to stand them in good stead through life.

\title{
REFERENCES
}

Clark, F. Le G. (1959). Proc. Nutr. Soc. 18, I.

Cope, Z. (1959). Proc. Nutr. Soc, 18, 6.

Drummond, J. C. \& Wilbraham, A. (1957). The Englishman's Food, and ed. London: Jonathan Cape. Medical Research Council: Committee upon Quantitative Problems in Human Nutrition (1924). Spec. Rep. Ser. med. Res. Coun., Lond., no. 87.

Morris, J. N. (1945). Lancet, 248, 743 .

\section{Human problems in Service feeding}

By J. A. Mullington, Armed Services Supplies Branch, Ministry of Agriculture, Fisheries and Food, Dean Bradley House, Horseferry Road, London, S.W.I

In introducing this talk, I must emphasize that I have no scientific or nutritional background, and that my experience with the feeding of servicemen has been limited to that of a provisioner.

I would also like to say how grateful I am for the advice and assistance I have received at all times from those concerned with the scientific and nutritional aspects of Service feeding.

The feeding of servicemen seems to me to give rise to more problems than any other group feeding, inasmuch as we have to remember:

(a) The services consist largely of young adults with healthy and hearty appetites, which are further enhanced by the open air life most lead.

(b) Men come from all walks of life and from all areas. We have therefore to deal with local and even national eating habits.

(c) We must maintain a ration that will keep the men fit and ready to undertake operations in any part of the world at short notice and under very adverse conditions.

(d) Overseas we must make the utmost use of suitable local items in order to conserve shipping. We must therefore be prepared to vary the ration to meet local conditions.

(e) When operations are in progress or until fresh supplies can be built up the serviceman must exist on tinned foods.

(f) Cooking facilities in the field are of necessity somewhat primitive and restricted and very often meals can only be provided as the tactical situation allows.

(g) For various reasons we must provide a large portion of the ration in kind, or lay down definite limits within which it will be provided, in order to ensure that the diet does its necessary work of keeping the men in fighting condition.

(h) As a public service, we are subjected to stringent financial supervision. We have therefore to keep cost continuously in mind, and the Services' food budget is costly. 
(j) Service feeding is communal, and suspicion and prejudice spread easily if food is of poor quality, if it is something not in normal use in the family and if it is felt that in any way the serviceman is being used as a guinea-pig. The introduction of new ideas therefore requires a well-planned and careful build up before being launched.

(k) Above all in Service feeding we must remember that the serviceman is fed in barracks, and not always under the best conditions. We must therefore ensure as far as we can, and finances will allow, that the food is of the best, well-cooked, and that the dining halls are well laid out. Unfortunately we are still suffering from the old barracks of past generations with their antiquated equipment and buildings, although action is being taken to improve them.

(1) Lastly in enumerating the problems I would emphasize that the serviceman is ultraconservative in his habits. Don't therefore spring new ideas on him, and don't make too much of the scientific approach. He is not too keenly interested in calories but he is most keenly interested in a well-done steak.

The above represent some of the problems we have to face. Now let us look at how the Services endeavour to settle them.

The first action is to draw up a simple basic ration, consisting of the different types of essential foods. The aim of this scale is to provide a sufficiency of nutriment, an adequate balance to cover the various meals and to ensure that the items are such as can be provided. Finally, having made the basic scale, to relate it to cost, and either to prune and alter it to the financial limits set, or put up a case for higher financial limits.

This scale is drawn up in consultation between the three Services, which consult their Service experts on provision, nutrition, catering and cost. When approved it is issued as a ration scale.

Similar action is taken in respect of rations for Commonwealth or Colonial Troops serving with the British Forces and then the advice and assistance of the Commonwealth and Colonial Governments and authorities are sought. Local customs and characteristics are taken into account, and great care is taken to ensure that religious and tribal customs are not offended. Thus we arrive at a number of basic scales, and in the last war these were many, and offered many problems.

Having decided on our basic scale the next step is to provide variety. It is met by the provision of alternatives to the basic item, based on generally accepted items; on the essential need for turnover of tinned reserves; on availabilities both normal and local; on seasonable and financial possibilities. The alternatives are normally related to a meal basis and the bill of fare is planned to effect the utmost variety possible.

In the Service of today the old cry of monotony has largely disappeared and in the hands of experienced caterers and cooks a wide variety of meals can be provided.

For troops overseas, the basic scale will be varied to take account of readily available and acceptable local items and of additions for special conditions of heat or cold. Thus in the Persian Gulf area we have a hot-weather supplement to the ration 
scale consisting of fruit juices, sugar and salt, and for service in places like Korea, we have higher basic scales to compensate for cold.

Any Service scale must be dictated to some degree by the necessity of holding reserves to meet operational contingencies. The consequence is that the serviceman has to accept a proportion of tinned foodstuffs even though fresh may be available, in order to turn over this reserve within its normal shelf life. Similarly in training use is made of the special packs, namely the $24 \mathrm{~h}$ ration and the Compo ration, which the Services have designed to meet operation conditions when fresh supply is impossible or for other reasons undesirable. For operational purposes the Services are always seeking lightness compatible with adequate nutrition and variety.

The way in which the basic scale with its alternatives is applied differs between the three Services according to the system of messing in operation. Under the Army system, the rations are issued mainly in kind. At home, however, part of the ration is converted into cash and in this way a small sum of money, at present $6 \frac{3}{4} \mathrm{~d} . / \mathrm{man} / \mathrm{day}$, is placed in the hands of the Messing Officer to enable him to take advantage of local availabilities, to effect some greater variation and to cope to some extent with marked preferences in the unit. In the Navy, the consumption of foodstuffs is regulated entirely on a cost basis by means of monetary allowances which reflect the cost of the ration provided for the soldier. This system has been found to be particularly adaptable and best suited to meet the requirements of the sailor ashore and afloat. The R.A.F. use a cash system similar to the Navy's at home and a ration system similar to the Army's in overseas Commands.

Each Service has its peculiar problems. The Navy, for example, has the difficulty of cooking and feeding in very confined spaces, especially in small ships. Submarines present their own special problems. In order to meet the extra physical and psychological strain imposed on the crews during long patrols when considerable periods may have to be spent beneath the surface, extra quantities of the more attractive foods have to be supplied. In submarines too, the avoidance of sullage is of particular importance when submerged and it, as well as the premium on space, are among the factors which have a bearing on the quantities, types and packs of foodstuffs required. Even in surface ships, it is sometimes necessary to make special arrangements for the feeding of the ship's company. Under action conditions it may not be possible for various reasons to use the store rooms and galleys and the normal messing arrangements have then to be modified to enable the crews to be fed at their action stations by making use of simplified menus, precooked foods and emergency cooking positions.

But whatever scale is used and wherever it is used the same basic principles are observed, namely a basic nutritional requirement to meet the conditions of the place where the man is serving, the maximum variety within the limits of availability and finance, the addition to the basic scale of supplements to meet special climatic conditions, provision to enable advantage to be taken of local availabilities (where expenditure is impossible provision is met by additions to the basic scale).

In conclusion, it is fair to say that Service feeding has advanced far since the days of Soyer, who did so much to give a first fillip to it. Today, properly handled 
and prepared, the Service ration provides a good standard of feeding, paying full attention to nutritional problems and taste.

That it is so, can probably be deduced from the fact that the young recruit gains rapidly in weight and physique on joining the Services, and that, although we draw our recruits from all walks and conditions of life, malnutrition is almost unknown in the Services, despite the rigorous and difficult conditions under which men have to serve at all times and in all parts of the world.

\title{
The feeding of women in industry
}

\author{
By Phoebe Roscoe, Catering Manager, Glaxo Laboratories Ltd, Greenford, \\ Middlesex
}

Catering for workers in industry is easier in one way than catering for some other large groups of people. They only consume about half their daily food while at work, and their working week is frequently only 5 days out of the 7 . And they usually have a certain amount of free choice as it is very seldom now that industrial canteens and staff lunch rooms offer nothing but one fixed meal. So that there is no question of planning balanced menus for each day or week.

On the other hand, a very wide choice of different types of foods is now demanded by industrial workers in order to satisfy all their varied likes and needs. It is particularly noticeable when catering for staff of different types--factory, clerical and technical. And it is the women who want the greatest range of choice, especially at lunch time.

Many women, particularly those living alone and cooking for themselves, like to make their lunch the principal meal of the day, and will buy soup, a main dish, vegetables and a sweet. Others again like something slightly lighter with less substantial main dishes such as fish cakes, croquettes, cheese dishes, cold meats and salads. Some want just a snack of the egg on toast or Welsh rarebit type. And finally there are those, usually girls under 18 or 20 , who often have nothing more than a plate of chips. This choice appears to be partly because they want to spend as much of their lunch time as possible dancing or playing games, and partly because they don't want to spend much money on food. Like many industrial firms we give our adolescents a very cheap lunch. Juniors under 18 years of age can have a full three-course meal for only Is. od. Yet in spite of it many girls prefer to spend only $8 \mathrm{~d}$. or $9 \mathrm{~d}$. on a lunch of chips and ice-cream.

Slimming is a very important factor in influencing what the women eat, even amongst the teenagers. They buy far more salads than men, many fewer steamed and milk puddings, and much more stewed and tinned fruit. Their idea of what constitutes a slimming diet is apt to be rather curious. We often have women who cannot decide what dish to take because they say they are slimming. If you suggest that cold meat with green salad might be suitable the answer will often be: 'No, thank you. 